\title{
Pulmonary tuberculosis preventive practices among Anibessa Bus users at Addis Ababa, Ethiopia: a cross-sectional study
}

\author{
Asmamaw Malede ${ }^{1}$, Biruhalem Taye ${ }^{2}$, Mengistu Legesse ${ }^{3}$, Ayal Debie ${ }^{4^{*}}$ and Agumas Shibabaw ${ }^{1}$
}

\begin{abstract}
Objective: Tuberculosis (TB) is a chronic infectious disease caused by Mycobacterium tuberculosis. Smear positive tuberculosis patients are responsible for up to $90 \%$ of transmission occurring in the community. However, little is known about pulmonary tuberculosis preventive practices among bus users in Ethiopia. This study aimed to assess the level of Pulmonary Tuberculosis (PTB) preventive practices and associated factors among bus users at Addis Ababa.

Results: Community based cross-sectional study was conducted among bus users at Addis Ababa. Participants were selected using systematic sampling technique. Overall, $50.5 \%$ of bus users had good practices on prevention of PTB at Addis Ababa. The odds of practicing prevention of PTB among participants who were attended secondary school ( $A O R=4.63 ; 95 \% \mathrm{Cl} 2.62,11.17)$ and higher education ( $\mathrm{AOR}=2.86: 95 \% \mathrm{Cl} 1.13,7.73$ ), resided at Addis Ababa $(A O R=2.51 ; 95 \% \mathrm{Cl} 1.61,5.21)$, knowledgeable about PTB (AOR $=4.12 ; 95 \% \mathrm{Cl} 3.14,5.70)$, and using mass media $(A O R=2.14 ; 95 \% \mathrm{Cl} 1.78,4.27)$ as a source of information were higher than the odds of their respective counterparts. The overall practice of pulmonary tuberculosis prevention among city bus users in the study area was low. Therefore, enhancing educational opportunity and increase community awareness about the causes, risk factors and means of transmission using mass media might improve the practices of PTB prevention during bus transportation.
\end{abstract}

Keywords: PTB, Preventive practices, Factors, Bus users, Ethiopia

\section{Introduction}

Tuberculosis (TB) is a chronic infectious disease caused by Mycobacterium tuberculosis mainly, and occasionally caused by Mycobacterium tuberculosis complex [1]. TB is most commonly transmitted by inhalation of infected droplet nuclei, which are discharged in the air when somebody with untreated sputum-positive pulmonary TB during coughing, sneezing, talking or spiting. In addition, consumption of raw milk containing Mycobacterium bovis is also a possible way of getting infected by $\mathrm{TB}$ [2]. Smear positive TB patients are responsible for up to $90 \%$ of transmission occurring in the community [3].

\footnotetext{
*Correspondence: debieayal@gmail.com

${ }^{4}$ Department of Health Systems \& Policy, College Medicine and Health Sciences, Institute of Public Health, University of Gondar, P.O.Box 196, Gondar, Ethiopia

Full list of author information is available at the end of the article
}

The national population-based survey in 2011 revealed that the prevalence of smear positive pulmonary TB in Ethiopia among adults and all age groups was 108 and 63 per 100,000 population. The prevalence of smear and/or culture positive confirmed TB for persons aged 15 years and above was 277 per 100,000 [4, 5].

Ethiopia is one of the 27 high burden MDR TB countries ranking 15th with more than 5000 estimated MDRTB patients annually and one of the four countries in Africa along with South Africa, Nigeria and Democratic Republic of Congo. The estimated MDR TB cases in Ethiopia were $1.6 \%$ and $12 \%$ among all new and previously treated TB cases, respectively [6]. Ethiopia is one of the high TB, TB/HIV and MDR-TB burden countries worldwide. The estimated TB case detection rate in Ethiopia has been consistently low; the WHO estimates $64 \%$ for all forms [6]. The burden of TB is increasing with alarming rate due to various factors including poverty, population 
growth, migration and HIV/AIDS. But a significant problem lies with the fact that many cases remain undiagnosed [7].

The tubercle bacilli have a high risk particularly in overcrowded settings like areas having no adequate ventilation and light because the bacilli can survive in the dark for long periods and this implies that transmission usually occurs indoors [8]. Casual or random contact, mass public transport and genetic susceptibility are the main factors for epidemics of TB in recent years. Mass public transport is playing the primary role in casually close contact or overcrowded conditions which can facilitate the transmission of PTB [9]. Creating awareness about TB transmission preventive practices especially in high risky or overcrowded conditions were one of the major stop TB strategy to achieve the Millennium Development Goals (MDGs) [10].

However, there was no enough evidence about TB preventive practices particularly among bus users in Ethiopia. Therefore, this study was aimed to address PTB preventive practices and factors associated among Anibessa bus users at Addis Ababa, Ethiopia.

\section{Main text \\ Methods \\ Study setting and design}

A community based cross-sectional study was conducted among bus users at Addis Ababa city from March to June, 2012. In the year 2007 , the population of the city was estimated to be 2.74 million; from this $52.4 \%$ of the residents were females [11].

\section{Population and sampling procedure}

All Anibessa bus users at Addis Ababa were the source population, while bus users in the selected travel routes of Anibessa bus at Addis Ababa were the study population. Participants who were mentally ill as well as their age less than 18 years during the data collection period were excluded from the study.

Sample size was determined using single population proportion formula with an assumption of proportion (p) $=50 \%$, 95\% level of confidence, $5 \%$ margin of error (d), and $10 \%$ non-response rate. The final sample size was 422 . Anibessa city bus service enterprise has a total of 92 travel routes. From these routes, 23 were selected though lottery. Then, the participants were selected using systematic random sampling technique after proportionally allocating the number of participants to each routes of travel based on the bus numbers.

\section{Measurements}

PTB preventive practices, the dependent variable, was measured by using five item questions and participants who scored above $60 \%$ were considered as having good preventive practices, while respondents scored $60 \%$ and below of the total practice measuring score were having poor practice. Furthermore, the attitude of participants was measured using twelve item questions and those who scored $60 \%$ and above were considered as having favorable attitude towards PTB prevention. On the other hand, the knowledge of respondents about PTB was measured using 20 item questions and those who had scored 60\% and above were considered as knowledgeable.

\section{Data collection tools and quality control}

Data was collected through semi-structured interviewer administered questionnaire adopted from reviewing different literatures. The questionnaire was first prepared in English language, and translated to Amharic and finally, back to English in order to ensure its consistency. Pretest was conducted among 20 participants and necessary modification was made based on the pretest findings. Six clinical nurses for data collectors, and 2 health officers for supervisors were recruited. A day training was given to data collectors and supervisors on the basic techniques of data collection. The data was cleaned by supervisors and principal investigators on daily basis for ensuring its completeness and consistency.

\section{Data management and analysis}

The data was entered and analyzed using Epi info version 7 and STATA Version 13, respectively. Descriptive statistics such as mean, frequency, and percentages were presented using tables, and figures. Binary logistic regression model was used to identify factors significantly associated with PTB preventive practices. Adjusted odds ratio (AOR) with 95\% confidence interval (CI) and p-value $<0.05$ were used to determine the strengths and factors associated with PTB preventive practices.

\section{Results}

\section{Socio-demographic and economic characteristics}

A total of 408 Addis Ababa city bus users were participated with a response rate of $96.7 \%$. The median age of the participants were 25 years with interquartile range of 12.25. Nearly, two-thirds of the participants were males and unmarried. About $44.6 \%$ were resided in Addis Ababa and $70.1 \%$ of bus users were Orthodox Christian. More than one-third of respondents reported that they always had used Anibessa bus. More than half of the participants monthly household income were less than ETB 500 (Table 1).

\section{Knowledge of participants about PTB}

Nearly, two-third participants reported that cough of 2 weeks and bloody sputum were among the major 
Table 1 Socio-demographic and economic characteristics of bus users at Addis Ababa, 2012

\begin{tabular}{|c|c|c|c|}
\hline Variables & Category & Frequency & Percent (\%) \\
\hline \multirow[t]{2}{*}{ Sex } & Male & 279 & 68.4 \\
\hline & Female & 129 & 31.6 \\
\hline \multirow[t]{3}{*}{ Age group (in years) } & $18-25$ & 200 & 49.0 \\
\hline & $26-35$ & 127 & 31.1 \\
\hline & $\geq 36$ & 81 & 19.9 \\
\hline \multirow[t]{4}{*}{ Religion } & Orthodox & 286 & 70.1 \\
\hline & Catholic & 6 & 1.47 \\
\hline & Muslim & 60 & 14.7 \\
\hline & Protestant & 56 & 13.7 \\
\hline \multirow[t]{2}{*}{ Marital status } & Single & 247 & 60.5 \\
\hline & Married & 161 & 39.5 \\
\hline \multirow[t]{5}{*}{ Ethnicity } & Amhara & 171 & 41.9 \\
\hline & Oromo & 122 & 29.9 \\
\hline & Gurage & 75 & 18.4 \\
\hline & Tigray & 16 & 3.9 \\
\hline & Others & 24 & 5.9 \\
\hline \multirow[t]{5}{*}{ Educational status } & Unable to read and write & 59 & 14.5 \\
\hline & Able to read and write & 35 & 8.6 \\
\hline & Primary school & 81 & 19.9 \\
\hline & Secondary school & 88 & 21.6 \\
\hline & College and above & 145 & 35.5 \\
\hline \multirow[t]{3}{*}{ House hold monthly income } & $\mathrm{ETB}<500$ & 211 & 51.7 \\
\hline & ETB 500-1000 & 98 & 24.0 \\
\hline & $E T B \geq 1000$ & 99 & 24.3 \\
\hline \multirow[t]{6}{*}{ Occupation } & Student & 57 & 14.0 \\
\hline & Merchant & 35 & 8.6 \\
\hline & Unemployed & 127 & 31.1 \\
\hline & Government employed & 71 & 17.4 \\
\hline & Private employed & 94 & 23.0 \\
\hline & Others & 24 & 5.9 \\
\hline \multirow[t]{2}{*}{ Residence } & Out of Addis Ababa & 226 & 55.4 \\
\hline & Addis Ababa & 182 & 44.6 \\
\hline \multirow{2}{*}{ Frequency of bus use } & Some times & 251 & 61.5 \\
\hline & Always & 157 & 38.5 \\
\hline
\end{tabular}

symptoms of pulmonary tuberculosis, respectively. Moreover, $52.8,55.65$, and $52.7 \%$ of bus users stated that closing of bus windows during travelling, coughing and sneezing could transmit PTB, respectively. On top of this, more than half of participants recognized that PTB could be caused by germs or bacteria's, and about $62.3 \%$ described overcrowding condition such as using city bus might be a risk factor for PTB transmission and $96.8 \%$ of participants described that PTB is a curable disease. More than half $(52.7 \%)$ of the respondents were knowledgeable about the causes, risk factors, means of transmission, signs, and symptoms of pulmonary tuberculosis (Table 2).
Source of information and attitude towards prevention of TB More than $95 \%$ of the participants were heard about the disease pulmonary tuberculosis. The source of information for more than $80 \%$ of bus users were mass media. Furthermore, about $64 \%$ of the participants who had unfavorable attitude towards PTB preventive practices (Additional file 1: Figure S1).

\section{PTB preventive practices}

About $55 \%$ of bus users were covering their mouth and nose during coughing and sneezing for preventing PTB transmission during transportation. More than $19 \%$ of 
Table 2 Knowledge of participants about PTB among bus users at Addis Ababa, 2012

\begin{tabular}{lrrrr}
\hline Variables & \multicolumn{4}{l}{ Frequency } \\
\cline { 2 - 5 } & Yes & $\%$ & No & $\%$ \\
\hline Signs and symptoms of PTB & & & & \\
Cough of 2 weeks & 261 & 64.0 & 147 & 36.0 \\
Bloody sputum & 247 & 60.5 & 161 & 39.5 \\
Weight loss & 201 & 49.3 & 207 & 50.7 \\
Loss of appetite & 204 & 50.0 & 204 & 50.0 \\
Mode of PTB transmission & & & & \\
Closing of bus windows & 240 & 58.8 & 168 & 41.2 \\
Inadequate ventilation and light & 43 & 10.5 & 365 & 89.5 \\
Coughing & 227 & 55.6 & 181 & 44.4 \\
Talking & 197 & 48.3 & 211 & 51.7 \\
Sneezing & 215 & 52.7 & 193 & 47.3 \\
Lip kissing & 175 & 42.9 & 233 & 57.1 \\
Improper disposal of sputum & 243 & 59.6 & 165 & 40.4 \\
Causes and risk factors for PTB & & & & \\
Germs/bacteria is a cause for TB & 227 & 55.6 & 181 & 44.4 \\
Cigarette smoking & 122 & 29.9 & 286 & 70.1 \\
Overcrowding situation & 254 & 62.3 & 154 & 37.8 \\
PLHIV & 249 & 61.0 & 159 & 39.0 \\
Poor people & 177 & 43.4 & 231 & 56.6 \\
Prisoners & 155 & 38.0 & 253 & 62.0 \\
Rx of PTB & & & & \\
TB is curable & 395 & 96.8 & 13 & 3.2 \\
Defaulting anti-TB causes incurable & 274 & 67.2 & 134 & 32.8 \\
Defaulting anti-TB causes drug resistance & 190 & 46.6 & 218 & 53.4 \\
Knowledgeable about PTB & 215 & 52.7 & 193 & 47.3 \\
\hline
\end{tabular}

participants were opening windows and about $50 \%$ of bus users were properly disposing their sputum, tried to get early diagnosis and treatment when suspecting the disease. Nearly, half of the participants (50.5\%) had good practices on prevention of PTB among bus users in the study area (Additional file 2: Figure S2).

\section{Factors associated with PTB preventive practices}

Binary logistic regression model was used for multivariable analysis. Furthermore, AOR and p-value less than 0.05 were used to determine the strength and factors associated with PTB preventive practices. The odds of practicing prevention of $\mathrm{PTB}$ among participants attended secondary school $(\mathrm{AOR}=4.63 ; 95 \%$ CI 2.62 , 11.17) and higher education $(\mathrm{AOR}=2.86$; $95 \% \mathrm{CI} 1.13$, 7.73) were 4.63 and 2.86 times higher than the odds of participants who were unable to read and write, respectively. The odds of practicing prevention of PTB among respondents resided at Addis Ababa $(\mathrm{AOR}=2.51 ; 95 \% \mathrm{CI}$ $1.61,5.21)$ were 2.51 times higher than the odds of practicing among participants resided out of Addis Ababa.
The odds of practicing prevention of PTB among knowledgeable bus users about PTB (AOR $=4.12$; 95\% CI 3.14, 5.70) and participants using mass media $(\mathrm{AOR}=2.14$; $95 \%$ CI $1.78,4.27$ ) as a source of information were 4.12 and 2.14 times higher than that of the odds of practicing with their respective counterparts (Table 3 ).

\section{Discussion}

This study aimed to assess the level of PTB preventive practices and associated factors among Anibessa bus users at Addis Ababa, Ethiopia. The finding showed that nearly half of the participants (50.5\%) had good PTB preventive practices. This was comparable with the study done in Thailand refugees (55.5\%) [12]. Furthermore, this result was lower than that of studies conducted in Eastern Amhara region covering mouth and nose practice while coughing (66.6\%) [13] and Tarlac city (61\%) [14]. However, it was higher than studies conducted in Eastern Amhara region (45.3\%) [13], Gambella (45.5\%) [15], Iraq (38.2\%) [16], and Nigeria (32\%) [17]. The possible explanation for this difference might be due to difference in study design, area, period as well as participants.

The odds of practicing prevention of PTB among participants attended secondary school and higher education were 4.63 and 2.86 times higher than the odds of participants who were unable to read and write, respectively. This find was consistent with studies done in Tigray, Ethiopia, Kenia, and India [18-20]. The possible explanation might be due to respondents attended secondary and above education could be analyzed the economic burden and psychological consequences of the disease. The other justification could be educated bus users might have positive attitude to apply preventive practices of PTB.

The odds of practicing prevention of PTB among respondents resided at Addis Ababa were 2.51 times higher than the odds of practicing among participants resided out of Addis Ababa. This might be due to accessibility of getting information about pulmonary tuberculosis can be relatively high as a result of the availability of health facilities and mass media in Addis. The other justification might also participants in Addis could be educated and might know the means of prevention for PTB transmission.

Despite a higher proportion of the participants have heard about TB, but nearly half of the respondents had poor knowledge about the cause, risk factors, mode of transmissions, treatments, symptoms, and signs of the disease. Moreover, this study revealed that the study participants had basic knowledge about the symptoms of TB and its modes of transmission. This result was consistent with the studies in Crotia, Madagascar, Ethiopia, Brazil, and India [21-25]. The most frequently reported symptom by the participants was coughing. The odds of practicing prevention of PTB among knowledgeable bus 
Table 3 Factors associated with PTB preventive practices among bus users at Addis Ababa, 2012

\begin{tabular}{|c|c|c|c|c|c|}
\hline \multirow[t]{2}{*}{ Variables } & \multirow[t]{2}{*}{ Category } & \multicolumn{2}{|c|}{ PTB preventive practice } & \multirow[t]{2}{*}{ COR $(95 \% \mathrm{Cl})$} & \multirow[t]{2}{*}{ AOR $(95 \% \mathrm{Cl})$} \\
\hline & & Good & Poor & & \\
\hline \multirow[t]{5}{*}{ Educational status } & Unable to read and write & 17 & 42 & 1 & 1 \\
\hline & Able to read and write & 3 & 32 & $0.23(0.06,0.86)$ & $0.21(0.08,1.31)$ \\
\hline & Primary school & 30 & 51 & $1.45(0.71,2.99)$ & $1.37(0.59,3.87)$ \\
\hline & Secondary school & 64 & 24 & $6.59(3.16,13.71)$ & $4.63(2.62,11.17)^{*}$ \\
\hline & College and above & 92 & 53 & $4.29(2.22,8.27)$ & $2.86(1.13,7.73)^{*}$ \\
\hline \multirow[t]{2}{*}{ Residence } & Out of AA & 97 & 129 & 1 & 1 \\
\hline & AA & 109 & 73 & $1.99(1.34,2.95)$ & $2.51(1.61,5.21)^{*}$ \\
\hline \multirow[t]{2}{*}{ Sex } & Male & 140 & 139 & 1 & 1 \\
\hline & Female & 66 & 63 & $1.04(0.69,1.58)$ & $1.18(0.87,2.68)$ \\
\hline \multirow[t]{3}{*}{ Age in years } & $18-25$ & 94 & 106 & 1 & 1 \\
\hline & $26-35$ & 67 & 60 & $1.26(0.81,1.97)$ & $1.15(0.69,1.68)$ \\
\hline & $\geq 36$ & 45 & 36 & $1.41(0.84,2.37)$ & $1.04(0.57,1.91)$ \\
\hline \multirow[t]{2}{*}{ Marital status } & Unmarried & 119 & 128 & 1 & 1 \\
\hline & Married & 87 & 74 & $1.26(0.85,1.88)$ & $1.01(0.61,1.65)$ \\
\hline \multirow[t]{2}{*}{ Knowledge about PTB } & Not knowledgeable & 72 & 121 & 1 & 1 \\
\hline & Knowledgeable & 134 & 81 & $2.78(2.12,3.84)$ & $4.12(3.14,5.70)^{*}$ \\
\hline \multirow[t]{2}{*}{ Attitude towards PTB prevention } & Unfavorable & 127 & 135 & 1 & 1 \\
\hline & Favorable & 79 & 67 & $1.25(0.83,1.88)$ & $1.36(0.89,2.10)$ \\
\hline \multirow[t]{2}{*}{ Using mass media } & No & 28 & 42 & 1 & 1 \\
\hline & Yes & 178 & 160 & $1.67(1.17,3.19)$ & $2.14(1.78,4.27)^{*}$ \\
\hline
\end{tabular}

* Significant at $\mathrm{p}$-value $<0.05$

users about PTB were 4.12 higher than that of the odds of practicing with their counterparts. This finding was supported by studies conducted in Gambella, Ethiopia, Tajikistan, and Nigeria $[15,17,26]$. The possible explanation might be due to bus users who know about the causes, risk factors, means of transmission, and prevention might prone to practice their knowledge into practice.

Most of bus users mentioned that mass media was their main sources of information about TB which was similar to other findings in Lahore, Iraq, and Pakistan [14, 16 , 27]. The odds of practicing prevention of PTB among participants using mass media as a source of information were 2.14 times higher than that of the odds of practicing with non-users. This might be due to participants might give a chance to understand well on how to practice prevention of PTB and analyze the social, economic and health related crises as a result of acquiring the disease.

The overall practice of pulmonary tuberculosis prevention among city bus users was low. Therefore, educating the community to cover their mouth and nose during coughing and sneezing. Accordingly, awareness creation of bus users about proper disposal of their sputum and to open the bus windows during transportation. Additionally, community awareness about the causes, risk factors and means of transmission might improve the practices of PTB prevention during bus transportation.

\section{Limitation}

- The cross-sectional study could not assess temporality of the cause-effect relationships.

- The 95\% confidence intervals for the odds ratios for some variables was too wide, this might lower the power of association.

\section{Additional files}

Additional file 1: Figure S1. Source of information and attitude towards PTB preventive practices among bus users at Addis Ababa, 2012.

Additional file 2: Figure S2. PTB preventive practices among bus users at Addis Ababa, Ethiopia, 2012.

\section{Abbreviations}

AA: Addis Ababa; AOR: adjusted odds ratio; CSA: Central Statistical Agency; COR: crude odds ratio; MDGs: Millennium Development Goals; PTB: pulmonary tuberculosis; Rx: treatment; TB: tuberculosis; WHO: World Health Organization.

\section{Authors' contributions}

$A M, B T, M L, A D$, and $A S$ were involved in the conception, design, analysis, interpretation, report and manuscript writing. All authors read and approved the final manuscript. 


\begin{abstract}
Author details
${ }^{1}$ College of Medicine and Health Sciences, Wollo University, Dessie, Ethiopia.

${ }^{2}$ Akililu Lemma Institute of Pathobiology, Addis Ababa University, Addis Ababa, Ethiopia. ${ }^{3}$ College of Medicine and Health Sciences, Addis Ababa University, Addis Ababa, Ethiopia. ${ }^{4}$ Department of Health Systems \& Policy, College Medicine and Health Sciences, Institute of Public Health, University of Gondar, P.O.Box 196, Gondar, Ethiopia.
\end{abstract}

\section{Acknowledgements}

Authors would like to thanks for Addis Ababa University for their financial support. In addition, our gratitude goes to Addis Ababa city Health Bureau and the respective sub city health offices of Addis Ababa; staff members for their co-operation by providing necessary information. Finally, we would like thanks the study participants and data collector.

\section{Competing interests}

The authors declared that they have no competing interests.

\section{Availability of data and materials}

Data is available from the corresponding authors.

\section{Consent of publish}

Not applicable.

\section{Ethical approval and consent of participants}

Ethical approval was obtained from Institutional Review Board of Aklilu Lemma Institute of Patho-biology, Addis Ababa University. Formal permission letter also obtained from the respective Addis Ababa sub city health offices. The aim of the study was well explained to the study participants and verbal consent of participation was taken from each participant. The study subjects had informed about withdrawing from participating in the study at any time in the interviewing process. The confidentiality of the information obtained from participants was kept.

\section{Funding}

This study was sponsored by the principal investigator.

\section{Publisher's Note}

Springer Nature remains neutral with regard to jurisdictional claims in published maps and institutional affiliations.

Received: 20 September 2018 Accepted: 15 February 2019 Published online: 26 February 2019

\section{References}

1. Van Soolingen D. Molecular epidemiology of tuberculosis and other mycobacterial infections: main methodologies and achievements. J Intern Med. 2001;249(1):1-26.

2. WHO. Fact sheet on tuberculosis. Geneva: WHO; 2008.

3. Sekand JN, Neuhauser D, Smyth K, Whalen CC. Active case finding of undetected tuberculosis among chronic coughers in a slum setting in Kampala, Uganda. Int J Tuberc Lung Dis. 2009;13(4):508-13.

4. Kebede AZ, Tsegaye F, Lemma E, Onozaki I, Sismanidis C, et al. The first Ethiopian national population-based TB prevalence survey. Addis Ababa: Ethiopian Public Health Institute; 2011.

5. Federal Ministry of Health. Guidlines for clinical and programatic management of TB, TB/HIV and Leprosy in Ethiopia. 5th ed. Ethiopia: Addis Ababa; 2013.

6. World Health Organization. Global tuberculosis report. Geneva: WHO; 2014.

7. World Health Organization: TB as a public health problem. Department of communicable disease. 2004. http://www.hoseaorg/tb/publichealthhtm.

8. Harries AD, Maher D, Graham S. TB/HIV: a clinical manual. Geneva: World Health Organization; 2004
9. Jia Z-W, Li X-W, Feng D, Cao W. Transmission models of tuberculosis in heterogeneous population. Chin Med J. 2007;120(15):1360-5.

10. Uplekar M, Organization WH. The stop TB strategy: building on and enhancing DOTS to meet the TB-related millennium development goals. Geneva:WHO; 2006.

11. CSA. Statistical report of the 2007 population and housing census. Addis Ababa: Central Statistical Agency of Ethiopia; 2007.

12. Sreechat $S$, Hongsranagon P. Assessment of knowledge, attitude and preventive behavior of pulmonary tuberculosis among myanmar refugees in Ban Mai Nai Soi Temporary Shelter, Mae Hong Son, Thailand. J Health Res. 2013;27(6):391-8.

13. Esmael A, Ali I, Agonafir M, Desale A, Yaregal Z, Desta K. Assessment of patients' knowledge, attitude, and practice regarding pulmonary tuberculosis in eastern Amhara regional state, Ethiopia: cross-sectional study. Am J Trop Med Hyg. 2013;88(4):785-8

14. Bacay-Domingo MCN, Ong-Lim AL. A descriptive study of the knowledge, attitudes and practices on tuberculosis among treatment partners of pediatric patients in Tarlac City. Pediatric Infect Dis Soc Philip J. 2009;10(1):28-34

15. Bati J, Legesse M, Medhin G. Community's knowledge, attitudes and practices about tuberculosis in Itang special district, Gambella region, south western Ethiopia. BMC public health. 2013;13(1):734.

16. Hashim D, Al Dulayme A, Al Kubaisy W. Knowledge, attitudes and practices survey among health care workers and tuberculosis patients in Iraq. East Mediter Health J. 2003;10:493.

17. Duru CB, Iwu AC, Uwakwe KA, Diwe KC, Merenu IA, Chineke HN, Adaeze CA. Pulmonary tuberculosis preventive practices and its determinants among residents in communities in Orlu, Imo State, Nigeria. Int J Sci Healthc Res. 2016;1 (2):57-69.

18. Mesfin MM, Tasew TW, Tareke IG, Mulugeta GW, Richard MJ. Community knowledge, attitudes and practices on pulmonary tuberculosis and their choice of treatment supervisor in Tigray, northern Ethiopia. Ethiop J Health Dev. 2005;19(1):21.

19. Konda S, Melo C, Giri P. Knowledge, attitude and practices regarding tuberculosis among new pulmonary tuberculosis patients in a new urban township in India. Int J Med Sci Public Health. 2016;5(3):563.

20. Farhia Mohamud TW, Justus OS. Assessment of prevention behavioural practices among adult tuberculosis patients in Eastleigh Division, Nairobi County, Kenya. 2011. ir-library.ku.ac.ke/.../Assessment\%20of\%20preventi on\%20behavioural\%20practices\%....

21. Jurcev Savicevic A, Popovic-Grle S, Milovac S, Ivcevic I, Vukasovic M, Viali $\checkmark$, Zivkovic K. Tuberculosis knowledge among patients in out-patient settings in Split, Croatia. Int J Tuberc Lung Dis. 2008;12(7):780-5.

22. Rakotosamimanana S, Mandrosovololona V, Rakotonirina J, Ramamonjisoa J, Ranjalahy JR, Randremanana RV, Rakotomanana F. Spatial analysis of pulmonary tuberculosis in Antananarivo Madagascar: tuberculosisrelated knowledge, attitude and practice. PLoS ONE. 2014;9(11):e110471.

23. Gele AA, Sagbakken M, Abebe F, Bjune GA. Barriers to tuberculosis care: a qualitative study among Somali pastoralists in Ethiopia. BMC Res Notes. 2010;3(1):86.

24. Sudha G, Beena ET, Jawahar M, Josephine A, Selvi K, Sivasubramaniam S, Weiss M. Perceptions of gender and tuberculosis in a south Indian urban community. Indian J Tuberc. 2008:55:9-14.

25. Maciel E, Golub J, Peres R, Hadad D, Fávero J, Molino L, Bae J, Moreira C, Detoni VDV, Vinhas S. Delay in diagnosis of pulmonary tuberculosis at a primary health clinic in Vitoria, Brazil. Int J Tuberc Lung Dis. 2010;14(11):1403-10

26. Gilpin C, de Colombani P, Hasanova S, Sirodjiddinova U. Exploring TBrelated knowledge, attitude, behaviour, and practice among migrant workers in Tajikistan. Tubercu Res Treat. 2011;2011:548617.

27. Mushtaq MU, Shahid U, Abdullah HM, Saeed A, Omer F, Shad MA, Siddiqui AM, Akram J. Urban-rural inequities in knowledge, attitudes and practices regarding tuberculosis in two districts of Pakistan's Punjab province. Int J Equity Health. 2011;10(1):8. 